\title{
Gestão, monitoramento e avaliação dos planos de educação: \\ retrocessos e desafios
}

Education plans management, monitoring, and assessment:

setbacks and challenges

Gestión, seguimiento y evaluación de los planes educativos:

retrocesos y desafíos

\author{
JANETE MARIA LINS DE AZEVEDO* \\ Universidade Federal de Pernambuco, Recife- PE, Brasil.
}

JOÃO FERREIRA DE OLIVEIRA ${ }^{* *}$

Universidade Federal de Goiás, Goiânia- GO, Brasil.

\begin{abstract}
RESUMO: O artigo examina a gestão, o monitoramento e a avaliação, considerando o contexto de aprovação e de execução dos planos de educação. Problematiza conceitos fundamentais e apresenta a arquitetura criada para monitorar e avaliar os planos de educação. Evidencia o atual processo de desconstrução das políticas educacionais democráticas, assim como das proposições, ações e políticas hiperneoliberais e conservadoras a partir de 2016, destacando os desafios atuais para a retomada de um projeto educacional democrático e inclusivo.

Palavras-chave: Planos de educação. Controle social. Monitoramento e avaliação. Gestão democrática.
\end{abstract}

* Doutora em Ciências Sociais pela Universidade Estadual de Campinas. Pós-doutora pela Universidade de Paris e pela Universidad de Valência. Professora Titular da Universidade Federal de Pernambuco. E-mail: <janete.lins@gmail.com>.

** Doutor e pós-doutor em Educação pela Universidade de São Paulo. Professor Titular da Universidade Federal de Goiás. E-mail: <joao.jferreira@gmail.com>. 
ABSTRACT: The article examines management, monitoring, and assessment, considering the context of approval and execution of education plans. It questions fundamental concepts and presents the architecture created to monitor and assess education plans. It highlights the current process of deconstruction of democratic educational policies, as well as of hyper-neo-liberal and conservative proposals, actions, and policies as of 2016, highlighting the current challenges for the resumption of a democratic and inclusive educational project.

Keywords: $\quad$ Education plans. Social control. Monitoring and assessment. Democratic management.

RESUMEN: El artículo examina la gestión, el seguimiento y la evaluación, considerando el contexto de aprobación y ejecución de los planes educativos. Cuestiona conceptos fundamentales y presenta la arquitectura creada para monitorear y evaluar planes educativos. Destaca el actual proceso de deconstrucción de las políticas educativas democráticas, así como de las propuestas, acciones y políticas hiperneoliberales y conservadoras a partir de 2016, destacando los desafíos actuales para la reanudación de un proyecto educativo democrático e inclusivo.

Palabras clave: Planes educativos. Control social. Seguimiento y evaluación. Gestión democrática.

\section{Introdução}

$\mathrm{E}$

ste artigo traz reflexões sobre a gestão, o monitoramento e a avaliação da educação no Brasil, considerando sobretudo o contexto de aprovação e de execução dos planos de educação. Para tanto, destaca a noção de controle social e seus correlatos, afirmando a perspectiva que assumiu em relação à educação no Brasil, nos anos 1980, interligada ao princípio e práticas da gestão democrático-participativa. Trata também da sua reconfiguração e tensionamento, a partir dos anos 1990, em face do paradigma da gestão gerencial então emergente em nossa realidade.

A partir da problematização dessas noções, o artigo examina os elementos constitutivos, com a aprovação do Plano Nacional de Educação (PNE/2014-2024), da arquitetura criada para monitorar e avaliar os planos e políticas educacionais, com amplo envolvimento da sociedade civil organizada. 
Finalmente, destaca e reflete criticamente sobre o processo de desconstrução das políticas educacionais democráticas, assim como das proposições, ações e políticas hiperneoliberais e conservadoras que vêm sendo estabelecidas a partir do impeachment da presidente Dilma Rousseff (2011-2016).

O texto conclui com reflexões sobre os desafios para a retomada de um projeto educacional democrático e inclusivo em termos do direito à educação de qualidade para todos(as).

\section{Controle social e gestão democrática}

A noção de controle social e seus desdobramentos, de modo explícito ou subjacente, tem centralidade no presente artigo. Por isto, é importante ter presente que o controle social e a participação constituem dimensões intrinsecamente relacionadas e essenciais da gestão democrática da educação. No entanto, estes conceitos são polissêmicos, requerendo que se tenha presente seus múltiplos significados, cujas lógicas refletem concepções e interpretações sobre a estrutura social, o modo como se exerce o poder e a dominação, como se processam as relações sociais em uma determinada realidade em um dado momento histórico (AZEVEDO, 2013).

A noção de controle social surgiu desde o pensamento de autores clássicos, integrando-se às teorias funcionalistas, sendo afeta, desde então, ao campo da sociologia. Nestas vertentes, o controle se refere ao conjunto de normas, valores e práticas veiculados por grupos e instituições, de modo a garantir sua internalização pelos seus componentes. Tudo isso, buscando-se que as pessoas se adequem à ordem prevalecente, para que não haja comportamentos desviantes e rupturas no tecido social (GIDDENS; SUTTON, 2016; BOUQUET, 2012). Entretanto, outros significados lhes foram atribuídos, tanto no próprio campo da sociologia, quanto no das políticas públicas. Sua utilização, por exemplo, pode ser encontrada no sentido contrário do acima referido: o controle de segmentos da sociedade civil sobre as ações estatais, o que não anula que possa igualmente significar o controle da sociedade pelas instituições estatais. Trata-se de variações que se relacionam com o próprio modo de compreensão do Estado e da sociedade.

No campo das políticas sociais brasileiras, a noção em tela, nos anos 1980, se descolou da sociologia conservadora, assumindo a conotação da participação de representantes da população organizada na concepção e acompanhamento das políticas: por conseguinte, no controle e acompanhamento das ações do Estado. É desta perspectiva que se incorporou às definições para a educação, dada à atuação de determinados grupos, que a tomaram como sinônimo de participação na formulação, implementação e controle das políticas públicas.

A gestão democrática da educação, como outros conceitos também polissêmicos, é passível de deslocamentos no seu significado e, portanto, nas políticas que informa. 
Seu emprego, a partir dos anos 1980, se contrapunha a uma perspectiva de gestão adotada pela ditadura civil-militar ${ }^{1}$, que também continha elementos do patriarcalismo e do mandonismo (AZEVEDO, 2002). Em contraposição, seu emprego assumia o significado da participação da sociedade civil na formulação e acompanhamento das políticas, com vistas à construção da democracia social. Com este significado, expresso no que se passou a categorizar como "gestão democrática participativa", esta perspectiva se afirmou nas orientações da política educacional a partir dos anos 1980, sofreu arrefecimento nos anos 1990, voltou ao centro da cena no início dos anos 2000 e passou a ser colocada em causa fortemente desde 2016.

A gestão democrática participativa, nestes contextos, vem convivendo com outras orientações e práticas de gestão que têm estado em cena conforme a filosofia de ação de determinados governos e o tensionamento entre forças e projetos de sociedade em disputa. Assim, ainda é possível identificar elementos da concepção de gestão predominante no regime autoritário ou a presença forte do que se categoriza como gestão gerencial, cuja emergência entre nós data dos anos 1990. Ela surge no bojo das transformações do mundo capitalista que impõem novos padrões de regulação, articulados às orientações neoliberais, nos quais a educação possui centralidade.

Esses padrões, no geral, preconizam tão somente a democracia política, na medida em que defendem a diminuição do Estado, significando a progressiva supressão dos direitos sociais, cujas políticas são delegadas ao mercado. Portanto, têm trazido para as instituições públicas, para os sistemas de ensino e para as escolas modelos de gestão que são próprios das empresas privadas - conhecidos como a Nova Gestão Pública - ou práticas gerencialistas. O estímulo à competição e à meritocracia como valores, o sistema de bonificação, a avaliação por resultados são algumas de suas características, que acentuam o individualismo e, portanto, dificultam a participação e a gestão democrática, trazendo o controle social para a perspectiva do controle das instituições pelo Estado.

\section{Arquitetura, monitoramento e avaliação das políticas educacionais}

O controle social das políticas educacionais por meio, sobretudo, de conselhos, colegiados, fóruns etc., com representação significativa e envolvimento das entidades da área de educação. sempre foi uma preocupação central no processo de democratização da educação brasileira a partir da redemocratização do País nos anos 1980 (OLIVEIRA, 2010; 2018). Essa preocupação foi consubstanciada, em certa medida, nos princípios e parâmetros da gestão democrática da educação na Constituição Federal (CF) de 1988, na Lei de Diretrizes e Bases da Educação Nacional - LDB (Lei no 9.394/1996), nas leis do Fundo de Manutenção e Desenvolvimento do Ensino Fundamental e de Valorização do Magistério (Fundef) e do Fundo de Manutenção e Desenvolvimento da Educação Básica e de Valorização dos Profissionais da Educação (Fundeb), na Lei do PNE (2014-2024), dentre outras. 
Na segunda metade dos anos 2000, com a realização das conferências de educação e com a criação do Fórum Nacional de Educação (FNE), visando, em especial, a realização da Conferencia Nacional de Educação (Conae), em 2010, e a elaboração de propostas para o novo PNE, que viria a substituir o PNE (2001-2010), avançou-se mais claramente no papel da sociedade civil organizada na constituição de uma arquitetura institucional e colaborativa entre governos federal, estadual e municipais, visando ao monitoramento e à avaliação dos planos de educação, além da discussão permanente das problemáticas e das políticas, programas e ações em cada esfera administrativa com vistas a ampliar o direito à educação de qualidade para todos/as (OLIVEIRA et al., 2016; 2018).

O Governo Federal, no final de dezembro de 2010, encaminhou à Câmara dos Deputados o Projeto de Lei (PL) no 8.035/2010, que tratava do novo PNE, elaborado no âmbito do Ministério da Educação (MEC), após a realização da Conae 2010. Esse PL procurava concretizar o que previa a Emenda Constitucional (EC) nº 59, de 11 de novembro de 2009, que em seu Art. $4^{\circ}$ determina que

\begin{abstract}
a lei estabelecerá o plano nacional de educação, de duração decenal, com o objetivo de articular o sistema nacional de educação em regime de colaboração e definir diretrizes, objetivos, metas e estratégias de implementação para assegurar a manutenção e o desenvolvimento do ensino em seus diversos níveis, etapas e modalidades por meio de ações integradas dos poderes públicos das diferentes esferas federativas (BRASIL, 2009).
\end{abstract}

A aprovação do PNE, só veio a ocorrer por meio da Lei nº 13.005/2014, tornando-se um marco fundamental de conquista da sociedade brasileira (BRASIL, 2014). Essa lei assegurou maior participação e envolvimento da sociedade civil organizada na formulação de políticas educacionais e na estruturação de mecanismos de monitoramento e avaliação dessas políticas e estratégias concernentes ao futuro da educação no País. A aprovação do PNE e dos respectivos planos estaduais e municipais implicou enorme desafio para os entes federados, para os agentes do campo da educação e para a sociedade civil, em geral, que deveria agir de modo articulado e colaborativo para que os planos fossem acompanhados, monitorados e avaliados, de modo a serem articulados e alinhados na resolução dos grandes problemas históricos da educação brasileira (OLIVEIRA et al., 2016).

A elaboração ou reelaboração dos planos de educação, nas diferentes esferas administrativas, foi certamente uma conquista da sociedade, tendo em vista o alinhamento às 20 metas do PNE voltadas à universalização da educação básica obrigatória, ampliação das modalidades de educação, inclusão social e superação da discriminação, formação e valorização dos profissionais da educação, gestão democrática e ampliação dos recursos públicos para a educação pública etc. O PNE, juntamente com os planos estaduais e municipais, desenhou objetivamente um caminho para reduzir as desigualdades sociais e as assimetrias entre regiões, estados e municípios, pela via da colaboração e do efetivo 
envolvimento da sociedade na resolução dos problemas educacionais (OLIVEIRA et al., 2018; 2016).

Um dos grandes avanços do PNE foi a definição de uma estrutura e de uma estratégia ou processo de monitoramento e de avaliação dos planos (nacional, estaduais, distrital e municipais de educação). Para alcançar as metas municipais, estaduais e nacional, constantes do PNE, viu-se que seria preciso avançar na discussão e materialização do regime de colaboração, objetivando a construção dos planos de educação, a definição e a implantação de sistemáticas articuladas para o monitoramento e a avaliação permanente dos respectivos planos, tendo em vista corrigir rumos e buscar novas estratégias e meios

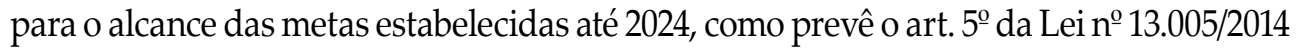
(BRASIL, 2014; OLIVEIRA et al., 2016).

A Lei n⿳ 13.005/2014 estabeleceu monitoramento e avaliações periódicas, realizados pelas seguintes instâncias: MEC; Comissão de Educação da Câmara dos Deputados; Comissão de Educação, Cultura e Esporte do Senado Federal; Conselho Nacional de Educação (CNE); Fórum Nacional de Educação ${ }^{2}$ (BRASIL, 2014). Além disso, definiu a realização de duas conferências nacionais de educação a serem concretizadas ao longo da vigência do PNE (2014-2024). Elas teriam também papel fundamental no esforço democrático e republicano de garantir o acesso, a permanência e de elevar a qualidade da educação no Brasil no período da vigência do Plano.

Tanto a EC nº 59/2009 quanto a Lei do PNE tornaram evidente que a concretização das metas do Plano implicaria uma melhor definição e articulação do regime de colaboração, o que se consubstanciaria na efetivação do Sistema Nacional de Educação (SNE) (OLIVEIRA, 2018; OLIVEIRA, OLIVEIRA, CARVALHO, 2017). A lei do PNE deixava claro que o SNE seria "responsável pela articulação entre os sistemas de ensino, em regime de colaboração, para efetivação das diretrizes, metas e estratégias do Plano Nacional de Educação" (Art. 13) (BRASIL, 2014). Isso implicava que, durante a vigência do PNE, considerando os diferentes planos de educação, seria necessário aperfeiçoar a articulação e a colaboração nas questões relativas ao financiamento, à formação e à valorização dos profissionais da educação, ao currículo, à avaliação, à gestão, dentre outros aspectos, tendo em vista a efetividade do SNE.

Criada em 2011, por orientação da Conae 2010, a Secretaria de Articulação com os Sistemas de Ensino (Sase/MEC) $)^{3}$ teria papel fundamental na definição de mecanismos e processos de orientação e assistência para elaboração dos planos de educação, bem como no monitoramento e avaliação dos mesmos, mas, sobretudo, na instituição do SNE, trabalhando ainda com o FNE nos termos da legislação aprovada e com os órgãos federais, a exemplo do Instituto Nacional de Estudos e Pesquisas Educacionais Anísio Teixeira (Inep), na produção e avaliação de indicadores para o controle social dos planos (OLIVEIRA et. al., 2016). 
Os desafios postos pela EC nํㅜ9/2009 e pela Lei do PNE exigiriam esforço articulado dos governos e da sociedade civil organizada. O planejamento coletivo indicava a produção e atualização permanente de diagnósticos para o acompanhamento e avaliação das metas, em diálogo com as instâncias formais de avaliação estabelecidas pela lei do Plano. A efetividade dos planos, como política de Estado, por sua vez, exigia uma cooperação e colaboração federativa ainda não existente no País (DOURADO, 2011; OLVEIRA, 2018). Era imperioso instituir processos de fiscalização e acompanhamento dos investimentos públicos, considerando cada uma das metas, sobretudo porque a meta 20 do Plano trazia claramente um aumento dos recursos para a educação, ao estabelecer que ao final da década o País deveria estar aplicando 10\% do Produto Interno Público (PIB) em educação. A experiência do Fundef e do Fundeb evidenciavam a necessidade de aperfeiçoar os mecanismos de assistência técnica e financeira da União, a eficiência e a eficácia da utilização desses recursos em cada sistema de ensino e a efetivação do controle social.

O entendimento era que o FNE e os seus correlatos Fóruns Estaduais de Educação (FEE), Fórum Distrital de Educação (FDE) e Fóruns Municipais de Educação (FME) ocupariam lugar estratégico nos processos de deliberações coletivas sobre os planos de educação e as diversas conferências de educação. Criado, inicialmente, por Portaria Ministerial (Portaria MEC nº 1.407, de 14 de dezembro de 2010), o FNE seria o espaço de interlocução entre a sociedade civil e o Estado, fruto de deliberação da Conae 2010. O FNE foi, posteriormente, instituído por Lei nº 13.005/2014. Dentre suas atribuições constava participar do processo de monitoramento e avaliação da execução do PNE e do cumprimento de suas metas (Art. 5). (BRASIL, 2014). Os fóruns de educação no âmbito dos estados, DF e municípios deveriam organizar-se de acordo com as orientações e os procedimentos estabelecidos regimentalmente pelo FNE (OLIVEIRA et al., 2016).

A Lei do PNE previa, em seu Art. 7º, §5\%, que "será criada uma instância permanente de negociação e cooperação entre a União, os Estados, o Distrito Federal e os Municípios" (BRASIL, 2014). Isso corroboraria na direção da institucionalização de espaços de negociação federativa, visando à coexistência coordenada e descentralizada de sistemas de ensino sob o regime de colaboração recíproca, com unidade, divisão de competências e responsabilidades compartilhadas. Em 2015, o MEC instituiu, por meio da Portaria nํ619, a Instância Permanente de Negociação Federativa, conforme previa a Lei do PNE. Caberia à Sase/MEC promover a interação da Instância Permanente com o FNE4

A aprovação do PNE (2014-2024) foi resultado de luta histórica da sociedade brasileira, no que se inclui a luta dos educadores, assim como a ampliação dos espaços de participação democrática, onde puderam atuar largamente entidades científicas, sindicatos, movimentos sociais e outros agentes significativos do campo da educação. A perspectiva do direito à educação, que guiou a luta política até aquele momento, implicava a continuidade da participação nos processos de elaboração dos planos, acompanhamento da sua implantação, monitoramento e avaliação. Em todas as esferas administrativas a educação 
pública deveria contar com a participação de agentes institucionais e individuais, governamentais ou não-governamentais, para discutir e apoiar o cumprimento das metas dos respectivos planos. Isso implicava incluir várias representações de entidades, além dos respectivos fóruns de educação, entendidos como espaços públicos relevantes para a discussão, implementação e avaliação das políticas educacionais (OLIVEIRA et al., 2016).

Além das instâncias formais de monitoramento e avaliação, instituídos pela Lei do PNE, entendia-se, no âmbito do FNE, que era fundamental o envolvimento da sociedade no planejamento, implementação e avaliação das ações educacionais. Acreditava-se ainda que os mecanismos de controle social, os órgãos colegiados, as instâncias de defesa e fiscalização dos recursos públicos etc. precisavam estar fortalecidos e atuantes na gestão do fundo público e no acompanhamento e na avaliação das metas previstas nos respectivos planos, o que implicava tornar transparentes os gastos públicos em educação pública e privada.

A própria lei do PNE (2014-2024) tinha estabelecido prazos intermediários que deveriam nortear o processo de monitoramento contínuo e avaliação periódica em todos os entes federados, o que incluía: publicação de estudos pelo Inep, a cada dois anos, para aferir a evolução das metas do PNE; realização de conferências de educação; elaboração dos planos de educação até junho de 2015; aprovação de leis específicas para a gestão democrática da educação até junho de 2016; institucionalização do SNE até junho de 2016, dentre outras (BRASIL, 2014). Além disso, o Art. 208 EC nº 59/2009 havia estabelecido a educação básica obrigatória e gratuita dos 4 (quatro) aos 17 (dezessete) anos de idade, assegurada inclusive sua oferta gratuita para todos os que a ela não tiveram acesso na idade própria. E essa obrigatoriedade deveria ser implementada progressivamente até 2016, com apoio técnico e financeiro da União. Portanto, caberia aos entes federados, de modo articulado e colaborativo, cumprir essa meta constitucional.

Metas e estratégias contidas no PNE, o que inclui mecanismos de monitoramento, de controle e avaliação, foram definidas com base em amplo processo democrático, envolvendo debates, negociações e acordos possíveis na defesa e na efetivação da educação como um direito social em todos os níveis. Neste contexto, ainda que tenham sido acomodadas outras perspectivas de gestão nestes acordos, a exemplo de elementos de orientações neoliberais, a predominância que se firmou no PNE foi a da perspectiva de gestão democrático-participativa, haja visto os mecanismos referidos no decorrer deste texto (OLIVEIRA, 2018).

No entanto, o fortalecimento de coalizão política capitaneada pela ultradireita e aliada a forças neofacistas passou a conduzir o Governo a partir de 2016, o que vem significando relegar as políticas sociais assim como políticas públicas em geral, sobretudo aquelas de maior pendor social. Nesse quadro é que se situam bloqueios ao desenvolvimento do PNE e de seus correlatos nos estados e municípios. Em contrapartida, medidas de política têm sido adotadas, aproximando cada vez mais a educação dos interesses 
privados, e de condição de mercadoria, segundo as bases de uma concepção ultraliberal que tem tomado o neoliberalismo como a nova razão do mundo (LAVAL; DARDOT, 2016).

\section{O PNE (2014-2024) e a regulação ultraconservadora da educação no Brasil}

Passados seis anos da aprovação do PNE (2014-2024), o que era esperança de que a educação fosse efetivamente uma política de Estado tornou-se praticamente letra morta nas proposições e ações do Governo Federal. A crise econômico-política, intensificada desde 2013, trouxe o protagonismo de velhas e novas forças conservadoras, representadas sobretudo por elites neoliberais e neoconservadoras, que, derrotadas nas eleições de 2014, orquestraram o golpe institucional contra a presidenta Dilma Rousseff, em 2016.

Desde então, muitos dos projetos que estiveram em disputa, dentre eles os voltados a favorecer o aprofundamento de uma regulação ultraneoliberal, passaram a encontrar terreno fértil à sua implementação. Michel Temer (na condição de vice de Dilma Roussef) ao assumir a Presidência da República, em nova coalizão política, abriu os caminhos que possibilitaram o atendimento de interesses das classes empresariais, segundo ditames da citada regulação (BOITO JUNIOR, 2016). Uma referência sobre suas principais políticas ratifica esta afirmação.

Marca significativa do período Temer, sem dúvida, constituiu a reforma trabalhista (Lei n⿳0 13.467/2017), viabilizada por um conjunto de mudanças na Consolidação das Leis do Trabalho (CLT), com a incorporação de novos dispositivos, que têm resultado na intensificação da precarização da força de trabalho (BRASIL, 2017). A justificativa para realizar a reforma se pautou na necessidade de adequar o trabalho no Brasil aos novos requerimentos dos processos produtivos. Difundiu-se também que viria ampliar as oportunidades de trabalho e a sua formalização, com diminuição do desemprego. A nova regulamentação faculta a contratação de trabalho temporário, autônomo exclusivo, de tempo parcial e a terceirização de atividade-fim (FILGUEIRAS, 2019). Ao alterar significativamente os direitos, houve a desregulamentação das relações de trabalho, com aumento dos níveis de precarização e de desemprego (KREIN; OLIVEIRA; FILGUEIRAS, 2019).

Medida também de grande impacto negativo constituiu a aprovação da Emenda Constitucional nº 95/2016 - a PEC do Teto dos Gastos. A emenda, justificada como modo de enfrentar a crise e o déficit estatal, estabelece novo regime fiscal, restringindo o atendimento de direitos ao determinar um limite para os gastos do Governo Federal por 20 anos (BRASIL, 2016). Conforme análise de especialistas, ao congelar as despesas primárias, reduzindo-as em relação ao $\mathrm{PIB}$, deixou-se de lado medidas de menos efeitos perversos, a exemplo da reforma fiscal com a taxação de grandes fortunas. A restrição de recursos para políticas de saúde, educação, cultura, habitação, segurança, proteção ao trabalho vem exacerbando as desigualdades (DWECK; OLIVEIRA; ROSSI, 2018). Neste quadro, metas e estratégias do PNE, como demonstra Amaral (2016), estão 
comprometidas. O aumento dos investimentos em relação ao PIB (7\% em 2019 e 10\% até 2024) inviabilizou-se.

Dentre outras ações, duas no campo da educação se destacaram. A reforma do ensino médio (Lei no 13.415/2017), e a homologação (em duas etapas) da Base Curricular Comum Nacional (BNCC), em terceira versão. A BNCC da educação infantil e do ensino fundamental foram homologadas em 2017 e a do ensino médio em 2018. O Governo restringiu a arena de decisões dessas ações, alargada desde o início dos anos 2002, desconsiderando proposições de forças progressistas (AGUIAR, 2018; AGUIAR; DOURADO, 2018). Em contraposição, privilegiou a interlocução com setores do empresariado mercantil que, embora sempre presentes nas disputas, desde então aprofundaram sua influência na definição das políticas.

A LDB, seguindo a Constituição Federal, já previa uma base comum, o que foi reiterado no PNE. No Governo Dilma Rousseff, versão preliminar da BNCC foi colocada em debate na sociedade civil e submetida à consulta pública, recebendo cerca de 12 milhões de contribuições, voltando ao MEC para análise e consolidação (AGUIAR, 2019). No mesmo processo, o Movimento pela Base Nacional Comum (MBNC), porta voz de interesse privatista, teve seu protagonismo alargado. Com o golpe de 2016, os resultados da ampla mobilização foram "esquecidos", voltando a BNCC a ser definida em espaço decisório restrito (UCZAK; BERNARDI; ROSSI; 2020).

A reforma do ensino médio, por sua vez, implantada por medida provisória em 2016, teve sua aprovação no Congresso em fevereiro de 2017. Seu instrumento legal (Lei no 13.415) trouxe alterações na LDB, na Lei do Fundeb e na CLT e instituiu a Política de Fomento à Implementação de Escolas de Ensino Médio em Tempo Integral. Sua justificativa principal foi a necessidade de tornar o ensino atraente e de melhor qualidade para a juventude, superando a obsolescência. Dessa perspectiva, promove a flexibilização curricular, dividindo o ensino médio em conteúdos previstos na BNCC em cinco áreas ou percursos formativos em que, teoricamente, os estudantes poderão optar. Há também a ampliação da carga horária para permitir o ensino de tempo integral, no entanto, com metas bem menores do que as previstas no PNE.

Dentre os problemas que essa reforma traz está a fragmentação da educação básica, ao tratar o ensino médio desarticulado da educação infantil e do ensino fundamental, pondo por terra a educação básica integrada como um direito igual para todos/as. Além disto, é questionável a flexibilização de conteúdos (com poucas disciplinas obrigatórias) bem como a opção por percursos formativos. São mudanças que fragmentam a formação dos jovens. A diferença de oferta dos itinerários ${ }^{5}$ pelos sistemas de ensino (já facultada) tende a acentuar a diferença entre regiões e entre a educação pública e privada (LIMA; MACIEL, 2018). Enfim, esses e outros problemas apontados pelos analistas evidenciam, mais uma vez, a tendência de uma educação pobre para os pobres e a busca de aproximar 
cada vez mais o ensino dos interesses do mercado, relegando a um segundo plano a educação básica como direito.

Se o Governo Temer, com suas medidas, bloqueou significativamente a viabilização do PNE, pode-se afirmar da intensificação destes bloqueios pelo Governo Jair Bolsonaro. Bolsonaro, também apoiado por coalizão de direita e, em certa medida, em continuidade ao governo Temer, tem buscado viabilizar um programa hiper neoliberal, complementado por valores e princípios conservadores.

A continuidade das orientações ultra neoliberais se manifestou na Reforma da Previdência - suprimindo mais ainda direitos de proteção social dos trabalhadores - no corte de recursos para a educação e a saúde, no desmantelamento de instâncias participativas para a condução das políticas sociais, na perseguição de professores e gestores de instituições federais de ensino, entre outras medidas.

Com três ministros da educação sem ainda ter completado dois anos de mandato, o Governo Bolsonaro, entre avanços e recuos, vem propondo ou colocado em ação medidas que se contrapõem à Constituição Federal de 1988, ao Estatuto da Criança e do Adolescente, à LDB e a outros marcos legais, demonstrando o aberto confronto com a ordem democrática. Nessa direção, são inúmeras as inciativas que procuram estabelecer perseguições político-ideológicas, bem aos moldes de regimes autoritários.

Entre tantas iniciativas, podem ser citadas tentativas de ressuscitar o ensino de Moral e Cívica na educação básica; combate à "ideologia de gênero" e à "doutrinação ideológica" nas escolas e universidades, em oposição ao pensamento crítico e criativo; destaque ao Programa Escola Sem Partido que propõe fortes restrições à liberdade dos professores em sala de aula; criação de comissão para revisar e monitorar o Exame Nacional do Ensino Médio (Enem) buscando censurar conteúdos. Do mesmo modo, foi a proposta de revisão de livros didáticos com concepções laudatórias sobre o golpe militar de 1964 e sobre o regime autoritário, e mudanças no Edital do Programa Nacional do Livro Didático (TORRES, 2019). São ações que relegam critérios democraticamente estabelecidos com base em padrões de qualidade e respeito ao pluralismo de ideias. A isto se soma o desrespeito ao princípio de gestão democrática da educação, como o modo de nomeação de reitores para universidades públicas e institutos, medidas coercitivas e de perseguição aplicadas a docentes e gestores, maculando a autonomia prevista nos marcos regulatórios.

Em contexto semelhante se insere o Programa Nacional de Escolas Cívico-Militares - (Pecim/Decreto nº 10.004/2019), experiência já encontrada em alguns entes federativos por iniciativa do poder local (MENDONÇA, 2020). O Pecim, de responsabilidade do Ministério da Defesa e do MEC, visa adotar, por adesão, o padrão de gestão das escolas militares em escolas públicas da educação básica, com a participação de militares aposentados. Ainda que o Programa traga entre seus objetivos contribuir para a consecução do PNE, o faz, contraditoriamente, tomando o modelo de gestão dos colégios militares como a solução para todos os problemas (BRASIL, 2019). 
Segundo o Ministério da Defesa, qualquer militar inativo, entre outras tarefas, pode auxiliar na gestão escolar e educacional, na manutenção da disciplina, na orientação de monitores, na melhoria da situação comportamental, na organização de eventos educacionais e cívicos. Os monitores (suboficiais, subtenentes e sargentos) podem se encarregar de tarefas como a melhoria do ambiente educativo, a redução da violência, do absenteísmo, e no desenvolvimento de valores morais (BRASIL, 2020a). A filosofia de ação do Pecim desconhece a gestão democrática, enaltecendo padrões dos colégios militares, cuja lógica é legítima para a formação de suas corporações. Entretanto, não pode ser tomada como modelo para a educação pública em geral cujos parâmetros visam à formação integral das pessoas como direito social.

O espaço desse artigo impossibilita balanço detalhado das medidas do governo. Todavia, cabe ainda mencionar a Política Nacional de Alfabetização, de 2019, a nova Política Nacional de Educação Especial (PNEE/Decreto nº 10.502/2020) e o Decreto nº 10.531, de outubro de 2020, que instituiu a Estratégia Federal de Desenvolvimento para o Brasil (EFD 2020-2031). Em relação à Política de Alfabetização, quase não houve diálogo com os entes federativos, desconhecendo iniciativas em curso, saberes acumulados e violando acordos estabelecidos no PNE (LEAL; MORAES, 2020). A PNEE faculta o atendimento dos alunos com deficiência em salas "especiais", desconsiderando os debates que construíram a política em vigência, apoiada em Convenção Internacional e na Emenda Constitucional no 59/2009.

Finalmente, a EFD 2020-2031 foi decretada visando a elevação da renda e da qualidade de vida da população e redução das desigualdades sociais até 2031. O documento destaca fortemente a necessidade de reformas fiscais como único meio para alcançar a estabilidade macroeconômica e viabilizar as prospecções. Apresenta cenários, desafios, metas e orientações para cinco áreas: econômica, institucional, infraestrutura, ambiental e social, esta última composta pela educação e saúde (BRASIL, 2020b).

A educação ou escolarização é tomada como meio de aumento da produtividade através do crescimento do capital humano, aos moldes dos postulados neoliberais, concepção que permeia todo o documento. Na área institucional, por exemplo, os órgãos públicos são instados a desenvolver competências visando à qualificação do planejamento e da gestão por resultados, em estreito alinhamento com a Nova Gestão Pública, que articula as orientações neoliberais à ação do Estado $^{6}$.

\section{Considerações finais}

Este artigo trouxe elementos para uma reflexão a respeito dos rumos do PNE (20142024) e de seus desdobramentos nos processos de monitoramento e avaliação das políticas de educação, tendo em vista os rumos imprimidos à sociedade brasileira desde 2016. Para tanto, com o apoio das noções de controle social e gestão da educação, procurou-se 
demonstrar tanto o processo de construção como os elementos constitutivos da arquitetura institucional destinada a monitorar os planos e as políticas de educação concernentes, o que ocorreu a partir da própria promulgação do PNE. Neste quadro, se apresentou um detalhado rol das medidas de política, evidenciando a ampla participação da sociedade civil e as disputas para o estabelecimento de dispositivos que tenderiam, em última instância, a garantir o controle social e a participação democrática no seu acompanhamento e implementação. Em seguida, o artigo procurou confrontar o contexto, descrito em sua primeira parte, com as principais definições, propostas e ações que estão sendo colocadas para a sociedade brasileira e para a educação, desde o impedimento da Presidente Dilma Rousseff.

Assim, tentou-se acentuar as características de políticas de educação recentes, que fogem de uma filosofia de ação democrático-participativa, tangenciando e congelando o que fora democraticamente estabelecido e negociado por meio do PNE. Trata-se, pois, da vivência de um contexto em que vem se agravando a situação do País no atendimento aos direitos e no combate às desigualdades de todos os níveis, em face das diretrizes ultra neoliberais, com neoconservadores que guiam ações do Governo Bolsonaro, agudizadas pela pandemia. Observam-se medidas voltadas para a desconstrução do Estado como agente econômico e social, ao tempo em que se amplia o alijamento da sociedade civil organizada dos espaços coletivos de discussão e deliberação das políticas e ações atinentes aos diferentes temas de interesse da sociedade brasileira, destacadamente os educacionais.

Faz-se necessário, pois, ampliar o debate público sobre a educação, resistir ao desmonte das políticas e ações construídas democraticamente e reconstruir as bases de um novo projeto educacional.

A aprovação e constitucionalização do Fundeb pelo Congresso Nacional trouxe certo alento e esperança aos educadores progressistas. Esta medida, a depender da sua regulamentação, pode contribuir para viabilizar algumas das metas e estratégias do PNE e da EC nº 59/2009, em termos de obrigatoriedade, expansão e qualidade da educação. A constitucionalização do custo aluno qualidade (CAQ) favorece, de princípio, que, em cada esfera administrativa, ocorra uma maior visibilidade e estruturação de mecanismos de controle social da educação. Isso poderá contribuir certamente na direção de retomar o PNE como epicentro das políticas educacionais e a volta da discussão do regime de colaboração, tendo por base a materialização do SNE.

Recebido em: 18/11/2020 e Aprovado em: 14/12/2020

\section{Notas}


1 A concepção de gestão das políticas públicas, no período da ditadura civil militar, se articulava a uma concepção de planejamento para a sociedade e seus setores com base numa racionalidade técnico-científica tomada como neutra. Assim, justificava-se uma modalidade de gestão da educação centralizada e controlada, baseada em pressupostos da teoria do capital humano.

2 No governo de Michel Temer, por meio da Decreto Executivo de 26 de abril de 2017 e da Portaria nº 577 de 27 de abril de 2017, houve alteração significativa e unilateral do calendário da Conferência Nacional de Educação de 2018 (Conae 2018) e uma desfiguração do Fórum Nacional de Educação (FNE), visando inserir entidades sem apreciação do Fórum e mais pessoas ligadas ao Governo, o que levou as entidades mais progressistas a deixarem coletivamente o FNE e a criarem o Fórum Nacional Popular de Educação (FNPE), bem como a realizarem a Conferência Nacional Popular de Educação, que ocorreu de 24 a 26 de maio de 2018, em Belo Horizonte/MG.

3 A Sase/MEC foi extinta no início do Governo Jair Bolsonaro, em 2019, o que evidenciava que o PNE e o processo de articulação com os entes federados e de participação da sociedade civil organizada não seguiriam na mesma direção dos governos de Lula da Silva (2003-2010) e Dilma Rousseff (2011-2016).

4 Essa Instância Permanente sofreu profunda alteração. por meio da Portaria n⿳ํㅜ 1.716, de 3 de outubro de 2019, do ministro da Educação, Abraham Weintraub. Desde então, ampliou-se significativamente a participação do MEC por meio dos seus secretários e de outros órgãos do ministério, além daqueles representantes do Conselho Nacional de Secretários de Educação (Consed) e da União dos Dirigentes Municipais de Educação (Undime). O Artigo 3ํㅡㄹ definiu que o "Ministro de Estado da Educação é membro nato e presidente da Instância Permanente de Negociação e Cooperação entre a União, os Estados, o Distrito Federal e os Municípios".

5 Quais sejam: Linguagens e suas Tecnologias; Ciência da Natureza e suas Tecnologias; Ciências Humanas e Sociais Aplicadas; Matemática e suas Tecnologias; e Formação Técnica e Profissional.

6 São ainda proposições do Governo Bolsonaro, em tramitação no Congresso Nacional, o projeto de homeschooling (educação domiciliar) (BARBOSA, 2016) e o Programa Universidades e Institutos Empreendedores e Inovadores - Future-se (FILGUEIRAS, 2019). Ambos estão ajustados ao conservadorismo educacional e à perspectiva da educação superior como mercadoria.

\section{Referências}

AGUIAR, Márcia Angela da Silva. Política Educacional e a Base Nacional Comum Curricular: o processo de formulação em questão. Currículo sem Fronteiras, online, v. 18, n. 3, p. 722-738, set./dez. 2018.

AGUIAR, Márcia Angela da Silva. Reformas conservadoras e a "nova educação": orientações hegemônicas no MEC e no CNE. Educação e Sociedade, Campinas, v. 40, e0225329, 2019.

AMARAL, Nelson Cardoso. PEC 241/55: a "morte" do PNE (2014-2024) e o poder de diminuição dos recursos educacionais. Revista Brasileira de Política e Administração da Educação, Goiânia, ANPAE: S. 1., v. 32, n. 3, p. 653-673, dez. 2016.

AZEVEDO, Janete Maria Lins. O Controle social, a participação e a gestão democrática da educação básica no contexto da regulamentação recente. Salto para o Futuro, online, v. 16, p. 13-22, 2013.

AZEVEDO, Janete Maria Lins. Implicações da nova lógica da ação do Estado para a educação municipal. Educação E Sociedade, Campinas, v. 20. n. 80, p. 49-72, 2002.

BARBOSA, Luciane Muniz Ribeiro. Homeschooling no Brasil: ampliação, do direito à educação ou via de privatização? Educação \& Sociedade, Campinas, v. 37, n. 134, p. 153-168, mar. 2016.

BRASIL. Constituição (1988). Constituição da República Federativa do Brasil. Brasília: Senado Federal, 1988.

BRASIL. Emenda Constitucional nº 59, de 11 de novembro de 2009. DOU 12/11/2009, Brasília, 2009. 
BRASIL. Lei nº 13.005 de 25 de junho de 2014. Aprova o Plano Nacional de Educação - PNE e dá outras providências. DOU de 26/06/2014, edição extra, Brasília, 2014.

BRASIL. Decreto № 10.004, de 5 de setembro de 2019. Institui o Programa Nacional das Escolas CívicoMilitares. Disponível em: https://www2.camara.leg.br/legin/fed/decret/2019/decreto-10004-5setembro-2019-789086-publicacaooriginal-159009-pe.html Acessado em 02 nov. 2020.

BRASIL. Ministério da Defesa. Gabinete do Ministro. Portaria n. 12 GM/MD, de 29 de janeiro de 2020. Estabelece regras para a seleção, contratação e capacitação de militares inativos das Forças Armadas para atuarem no Programa Nacional das Escolas Cívico-Militares - Pecin, em atendimento ao disposto no Decreto n. 10.004, de 5 de setembro de 2019, e dá outras providências. Brasília: Ministério da Defesa, $2020^{\mathrm{a}}$.

BRASIL. Decreto $n^{\underline{0}} 10.531$, de 26 de outubro de 2020. Institui a Estratégia Federal de Desenvolvimento para o Brasil no período de 2020 a 2031 Diário Oficial da União edição de 27 de outubro de 2020b.

BRASIL. Lei nº 9. 394, de 20 de dezembro de 1996. Estabelece as diretrizes e bases da educação nacional. Disponível em: http://www.planalto.gov.br/ccivil_03/leis/19394.htm. Acesso em: 19 nov. 2020.

BRASIL. Lei 13.467, de 13 de julho de 2017. Altera a Consolidação das Leis do Trabalho (CLT), aprovada pelo Decreto-Lei no 5.452, de $1^{\circ}$ de maio de 1943, e as Leis nos 6.019, de 3 de janeiro de 1974, 8.036, de 11 de maio de 1990, e 8.212, de 24 de julho de 1991, a fim de adequar a legislação às novas relações de trabalho. Brasília, 2017.

BRASIL. Lei $n^{0}$ 12.796, de 4 de abril de 2013. Altera a Lei no 9.394, de 20 de dezembro de 1996, que estabelece as diretrizes e bases da educação nacional, para dispor sobre a formação dos profissionais da educação e dar outras providências. Brasília, 2013.

BRASIL. Lei $n^{\circ}$ 11.274, de 6 de fevereiro de 2006. Altera a redação dos arts. 29, 30, 32 e 87 da Lei no 9.394, de 20 de dezembro de 1996, que estabelece as diretrizes e bases da educação nacional, dispondo sobre a duração de 9 (nove) anos para o ensino fundamental, com matrícula obrigatória a partir dos 6 (seis) anos de idade. Brasília, 2006.

BRASIL. Lei $n^{0} 11.494$, de 20 de junho de 2007. Regulamenta o FUNDEB e dá outras providências. Disponível em: http://www.planalto.gov.br/ccivil_03/_ato2007-2010/2007/lei/111494.htm. Acesso em 10 nov. 2010.

BRASIL. Lei $n^{0}$ 9.424, de 24 de dezembro de 1996. Dispõe sobre o Fundo de Manutenção e Desenvolvimento do Ensino Fundamental e de Valorização do Magistério, na forma prevista no art. 60, § 7º, do Ato das Disposições Constitucionais Transitórias, e dá outras providências Disponível em: http://www. planalto.gov.br/ccivil_03/leis/19424.htm. Acesso em 20 nov. 2020.

BRASIL. Ministério da Educação. Portaria nº 619, de 24 de junho de 2015. Institui a Instância Permanente de Negociação Federativa no Ministério da Educação. Disponível em: <http://pne.mec.gov.br/publicacoes>. Acesso em 16 out. 2020.

BRASIL. Ministério da Educação. Secretaria Executiva. Secretaria Executiva Adjunta. CONAE 2010 Construindo o sistema nacional articulado de educação: o plano nacional de educação, diretrizes e estratégias de ação [Documento Final]. Brasília: MEC/SE/SEA, 2010. Disponível em: <http://conae.mec.gov.br/>. Acesso em: 26 nov. 2020.

BRASIL. Presidência da República. Emenda Constitucional nº 95, de 15 de dezembro de 2016. Altera o Ato das Disposições Constitucionais Transitórias, para instituir o Novo Regime Fiscal, e dá outras providências. Brasília, 2016. 
BRASIL. Lei no 13.415, de 16 de fevereiro de 2017. Altera as leis nos 9.394, de 20 de dezembro de 1996, que estabelece as diretrizes e bases da educação nacional, e 11.494, de 20 de junho 2007, que regulamenta o fundo de manutenção e desenvolvimento da educação básica e de valorização dos profissionais da educação, a consolidação das leis do trabalho - CLT, aprovada pelo decreto-lei no 5.452 , de $1^{\circ}$ de maio de 1943, e o decreto-lei n 236, de 28 de fevereiro de 1967; revoga a lei no 11.161, de 5 de agosto de 2005; e institui a Política de fomento à implementação de escolas de ensino médio em tempo integral. Brasília, 2017.

BOITO JR, Armando. Os atores e o enredo da crise política. In: JINKINGS, Ivana. Porque gritamos Golpe. São Paulo: Boitempo Editorial, 2016.

BOUQUET Brigitte. Analyse critique du concept de contrôle social. Intérêts, limites et risques. Vie sociale, França, v. 1, n. 1, p. 15-28, 2012.

CERQUEIRA, Luciano. Os caminhos da Educação no Governo de Jair Bolsonaro. Brasil 247, Edição de 13 de abril de 2020. Disponível em: https://www.brasil247.com/blog/os-caminhos-da-educacao-nogoverno-de-jair-bolsonaro. Acesso em 10 nov.2020

DOURADO, L. F. (Org.). Plano Nacional de Educação (2011-2020): avaliação e perspectivas. 2. ed. Goiânia: Editora UFG; Belo Horizonte: Autêntica, 2011.

DWECK, Esther; OLIVEIRA, Ana Luiza Matos de; ROSSI, Pedro. (Coord.) Austeridade e retrocesso: impactos sociais da política fiscal no Brasil. São Paulo: Brasil Debate e Fundação Friedrich Ebert, 2018.

FILGUEIRAS, L. Estrutura e conjuntura: a economia política brasileira e o "Future-se". In: CRH-UFBA. Dossiê future-se: do governo/MEC e as implicações para a universidade e a sociedade. Salvador, 2019. Disponível em: https://gtfuturese.paginas.ufsc.br/files/2019/08/Dossie\%CC\%82-FUTURE-SEufba.pdf. Acesso em 20 nov. 2020.

GIDDENS, Anthony; SUTTON, Philip W. Conceitos essenciais da Sociologia. Trad. Claudia Freire. 1ํe ed. São Paulo: Editora Unesp, 2016.

KREIN, José Dari; OLIVEIRA, Roberto Veras; FILGUEIRAS, Vitor Araújo. (Orgs.). Reforma trabalhista no Brasil: promessas e realidade. $1^{a}$ ed. Campinas: Curt Nimuendajú, 2019.

LAVAL, Christian; DARDOT, Pierre. A nova razão do mundo: ensaios sobre a sociedade neoliberal. São Paulo: Editora Boitempo, 2016.

LEAL. Telma Ferraz; MORAIS, Artur. Avaliação da alfabetização e formação de professores alfabetizadores no Brasil: caminhos e descaminhos. Em aberto, Brasília, v. 33, n. 108, p. 27-43, mai./ago. 2020.

LIMA, Marcelo; MACIEL, Samanta Lopes. A reforma do Ensino Médio do Governo Temer: corrosão do direito à educação no contexto de crise do capital no Brasil. Revista Brasileira de Educação, Rio de Janeiro, v. 23, e230058, 2018.

MENDONÇA, Erasto Fortes. Escolas cívico-militares: cidadão ou soldadinhos de chumbo? Retratos da Escola, Brasília, v. 13, n. 27, p. 621-636, 2020.

OLIVEIRA, João. F. A educação básica e o PNE/2011-2020: políticas de avaliação democrática. Retratos da Escola, Brasília, v. 4, n. 6, p. 91-108, jan./jun. 2010.

OLIVEIRA, João F. et al. Planos Estaduais, Distrital e Municipais de Educação: Caderno Temático 4. Camaragibe. PE: CCS Gráfica e Editora, 2016. Série Cadernos ANPAE, vol. 29. 
OLIVEIRA, João F. LDB, PNE (2014-2024) e Construção do Sistema Nacional de Educação: avanços, tensões e perspectivas. In: Jorge Najjar; Maria Celli Vasconcelos. (Org.). A LDB e as politicas educacionais: perspectivas, possibilidades e desafios 20 anos depois. 1ed.Curitiba: Appris, 2018, v. 1, p. 30-45

OLIVEIRA, João F.; OLIVEIRA, Valdirene A.; CARVALHO, R. R. S. . O Plano Nacional de Educação (2014-2024) e a construção do Sistema Nacional de Educação no contexto do regime de colaboração. In: Magna França; Walter Pinheiro Barbosa Junior. (Org.). Políticas e Práticas educativas. 1ed.Natal: Caule de Papiro, 2017, v. 1, p. 50-70.

TORRES, Michelangelo. Um balanço do primeiro ano da política educacional do governo Bolsonaro. Disponível em: https://esquerdaonline.com.br/2019/12/21/um-balanco-do-primeiro-ano-da-politicaeducacional-do-governo-bolsonaro/. Acesso em 20 nov.2020.

UCZAK, Lucia Hugo; BERNARDI, Liane Maria; ROSSI, Alexandre José. O governo Temer e a asfixia dos processos de democratização da educação. Educação, Santa Maria, v. 45, jan./dez. 2020. 